\title{
Leveraging Enterprise Architecture for Digital Transformation Adaptation Challenges in Higher Education Institutions
}

\author{
Wan Faezah Abbas', Mohd Naz'ri Mahrin², Nurazean Maarop ${ }^{3}$ \\ ${ }^{1,2,3}$ Razak Faculty of Technology and Informatics, Universiti Teknologi Malaysia, Kuala Lumpur \\ ${ }^{1}$ Faculty of Computer and Mathematical Sciences, Universiti Teknologi MARA, Shah Alam \\ 1wfaezah@tmsk.uitm.edu.my
}

Article History: Received: 10 November 2020; Revised: 12 January 2021; Accepted: 27 January 2021; Published online: 05 April 2021

\begin{abstract}
The rapid proliferation and emergence of mobile, digital technologies, smartphone devices, big data, cloud computing and Internet of Things (IoT) have given rise to a new era of Digital Transformation (DT). DT is shifting not only technological advancements but also involves changes to business processes, organization structure, business models, managerial and culture. Higher Education Institution (HEI) are undergoing some forms of DT and is affected by these changes. Technology is changing the way many HEIs operate and to ensure survival, HEI needs to adapt to DT changes. However, HEIs are facing difficulties in adapting to DT. The main objective of this paper is to identify DT adaptation challenges in HEI based on literature review. Result from the literature review lists the HEI DT adaptation challenges and Enterprise Architecture (EA) is identified as a facilitator and enabler to support DT initiatives.

Keywords: Digital Transformation, Enterprise Architecture, Higher Education Institution, Adaptation
\end{abstract}

\section{Introduction}

Digital Transformation (DT) has become a new phenomenon with the rise of new digital technologies such as Internet of Things (IoT), big data, cloud computing, mobile systems and collaboration networks (Zimmermann, Schmidt, Bogner, Jugel, \& Möhring, 2018). DT is defined as the use of new digital technologies that enables major business improvements and influences all aspects of customers' life (Reis, Amorim, Melão, \& Matos, 2018). Apart from technology, DT involves changing of three key areas of an organization: customer experience, operational processes and business models (Nahrkhalaji, Shafiee, Shafiee, \& Hvam, 2018).

The DT is rapidly transforming organizations across industries such as healthcare, finance, logistics, education, manufacturing, retail, transportation, government agencies and agriculture (Dahlan, Mukhtar, Ahmad@Alias, \& Awang, 2017; Jauhar et al., 2015; Parviainen, Kääriäinen, Tihinen, \& Teppola, 2017). DT in education is inevitable as a result of increasing usage of technology in everyday life. It is necessary to develop DT in this digital era and the ability to understand and adapt to our education system (Balyer \& Öz, 2018). Digital technologies are changing HEIs and transcends across teaching and learning and higher education pedagogy. Rapid technology development is transforming HEI by using technologies in the teaching process (Limani, Hajrizi, Stapleton, \& Retkoceri, 2019).

Compared to other industries, education such as HEI in particular is left behind in the DT. Education is one of the latest industries that started to make changes because it is traditionally loyal to old methods and practices (Limani et al., 2019). HEIs trail behind other industries such as manufacturing, retail, financial services, and healthcare in DT journey with only 54\% of HEIs having a full and progressing DT strategy compared to at least $64 \%$ or more in other aforementioned industries in Asia. The study by Microsoft also demonstrated HEIs with established DT strategy will yield conclusive benefits in student engagement and empowered faculty (Microsoft, 2018).

Limani et al (2019) suggested that researchers should provide HEIs with enabling tools and methodologies for DT adaptation. In order to deal with DT uncertainties, HEI should develop on adaptation competencies in institutional digitization (Educause, 2018). However, there are challenges in adapting to DT that is faced by HEIs (Bond, Marín, Dolch, Bedenlier, \& Zawacki-Richter, 2018; Hussain et al,. 2016; Tarabasz, Selaković, \& Abraham, 2018).

Based on systematic review done by Gebayew et al. (2018), most of the researchers applied EA to assist DT in order to examine and reestablish the value mechanisms of the organization effectively and efficiently. EA approach should enable support digitization of products and services and easily adaptable to assist DT with new business models and technologies (Bogner \& Zimmermann, 2016). The main aim of this paper is to identify the DT adaptation challenges in HEI based on literature review. Moreover, literatures on EA as solution for DT in HEI is also reviewed. 


\section{Methodology}

In this paper, we examine and evaluate the literatures based on the following research questions: i) what are the DT adaptation challenges in HEI and ii) how EA facilitates DT in HEI? To answer these research questions, recent related published articles were searched from Scopus, Web of Science, IEEEXplore, Google Scholar and Emerald databases. Several keywords and their combinations have been used to examine the articles to get the relevant set of possible articles for this study. Keywords such as "digital transformation OR digitization", "adaptation OR adaptive", "higher education OR university" and "enterprise architecture OR EA" were used. A thorough analysis and synthesizing of materials from journals, proceedings, book chapters, and web articles were done to gather facts. In addition, there are several supporting literatures of DT adaptation challenges and EA as enabler to support DT initiatives were also taken into consideration and cited as references.

\section{Findings and Discussion}

At the organizational level, the major pressure on DT is the need to constantly adapt to meet the demands of changing environments (Brown, Fishenden, \& Thompson, 2014). DT places users at the heart of the corporate strategy. They expect companies to be able to adapt and customize to the changing needs. In order to face these expectations, organizations need to adapt and change their products and services according to user needs (Henriette, Feki, \& Boughzala, 2016). The increasing dynamics of technology impose significant challenges for enterprises since there is a constant need to adapt to changes due to DT (Gampfer, 2018). In order to remain successful, organizations have to adapt more quickly to the changing conditions of DT (Bughin \& Zeebroeck, 2017).

Based on the report by Capgemini (2018) stated that organizations are still struggling in adapting to DT. Six years after their original research, based on their survey of more than 1,300 executives in over 750 global organizations shows that there was no clear advancement in building capability and experience in driving DT. Organizations have realize it is difficult to adapt to the technology innovation changes and the research revealed that talent and culture are the major challenge in digital transformation (Buvat et al., 2018).

\subsection{Classification of Digital Transformation Adaptation Challenges in HEI}

In order to identify and distinguish the DT adaptation challenges in HEI, a classification of adaptation challenges review was done and extracted based on the literature review. Table 1 shows the list of challenges in adapting to DT in HEI. It can been seen from Table 1 there are six main DT adaptation challenges identified from the LR which are adapting to new learning environment and learning models, adapting to organizational structure and business process changes, financial constraints, digital initiatives and technology barriers, lack of digital strategic vision, and stakeholder digital literacy and expectations.

It is apparent from Table 1 that adapting to new learning environment and models and stakeholder digital literacy and expectations are the main challenges that HEIs faced in adapting to DT. New learning environment and models such as implementation of e-learning platforms, collaborative learning, game-based learning, personalized and adaptive learning needs to be adapted in higher education. HE systems is forced to adapt to global changes which requires new education model and environment in teaching and learning (Trifonov \& Shorokhova, 2019). The new generation of students' expectations are sophisticated as they are used to digital technologies. Therefore, lecturers need to be more creative and innovative in their digital teaching skills.

Table 1. Challenges in adapting to digital transformation in HEI

\begin{tabular}{|c|c|c|c|c|c|c|}
\hline $\begin{array}{l}\text { DT Adaptation } \\
\text { Challenges in HEI }\end{array}$ & $\begin{array}{l}\text { Adapting to } \\
\text { new } \\
\text { learning } \\
\text { environment } \\
\text { and models }\end{array}$ & $\begin{array}{l}\text { Changes to } \\
\text { organizational } \\
\text { structure and } \\
\text { business } \\
\text { process }\end{array}$ & $\begin{array}{l}\text { Financial } \\
\text { constraints }\end{array}$ & $\begin{array}{l}\text { Digital } \\
\text { initiatives } \\
\text { and } \\
\text { technology } \\
\text { barriers }\end{array}$ & $\begin{array}{l}\text { Lack of } \\
\text { digital } \\
\text { strategic } \\
\text { vision }\end{array}$ & $\begin{array}{l}\text { Stakeholder } \\
\text { digital } \\
\text { literacy and } \\
\text { expectations }\end{array}$ \\
\hline $\begin{array}{l}\text { (Gama, Vega, \& } \\
\text { Neira, 2018) }\end{array}$ & & $\checkmark$ & & & & \\
\hline (Haggans, 2015) & $\checkmark$ & & & & & \\
\hline $\begin{array}{l}\text { (Kaminskyi, } \\
\text { Yereshko, \& } \\
\text { Kyrychenko, 2018) }\end{array}$ & $\checkmark$ & $\checkmark$ & & $\checkmark$ & & \\
\hline (Maltese, 2018) & & & & $\checkmark$ & & $\checkmark$ \\
\hline (Nugraha, Sahroni, & & & & & $\checkmark$ & $\checkmark$ \\
\hline
\end{tabular}




\begin{tabular}{|l|l|l|l|l|l|l|}
\hline \& Latifah, 2018) & & & & & & \\
\hline (PWC, 2018) & & & & & $\checkmark$ & $\checkmark$ \\
\hline (Rodrigues, 2017) & & & $\checkmark$ & $\checkmark$ & $\checkmark$ & $\checkmark$ \\
\hline $\begin{array}{l}\text { (Tarabasz et al., } \\
\text { 2018) }\end{array}$ & $\checkmark$ & & & & \\
\hline $\begin{array}{l}\text { (Trifonov \& } \\
\text { Shorokhova, 2019) }\end{array}$ & $\checkmark$ & & & & $\checkmark$ & $\checkmark$ \\
\hline $\begin{array}{l}\text { (Zulfikar, Umri, } \\
\text { Hashim, \& Dahlan, } \\
\text { 2018) }\end{array}$ & $\checkmark$ & & & & & \\
\hline
\end{tabular}

HEIs lack clarity of digital strategic vision and most of them are still not ready for such evolution (Nugraha et al., 2018; PWC, 2018). It is important to have clear vision for the whole of DT in HEI in order to obtain an overview of DT in HEIs and determine its distinctive characteristics, implementations and processes (Benavides, Arias, Serna, Bedoya, \& Burgos, 2020).

DT has disrupt the traditional teaching and learning through digital initiatives such as usage of Massive Open Online Courses (MOOC), collaborative learning using mobile and digital media (Bond et al., 2018). There is a constant adaptation to new technology in HEI with the emergence of digital campus, digital classroom by utilizing technology for classroom with Virtual and Augmented Reality (VR and AR), interactive walls and also digital learning environment (Tarabasz et al., 2018). Nevertheless, digital initiatives and technology barriers is a challenge for HEIs in integrating the various technical solutions, difficulties in identifying the appropriate tools and supporting technologies, and barriers to embed using new technologies (Kaminskyi et al., 2018; Maltese, 2018).

Changes to HEIs organizational structure and business processes such as the creation of new organizational units for online education program and formalization of online exams is a challenge. Modification to organizational structures are necessary to exploit new technologies and able to point the way to new directions for DT in HEIs. HEIs should begin to transform pertaining to internal processes related to education process such as student admission and registration, and conducting education programmes to digitalization implementation in HEIs (Sandkuhl \& Lehmann, 2017).

Another challenge faced by HEIs is related to financial capability to accommodate DT. HEIs need reliable infrastructure and technology to sustain learning. Emerging technologies are often expensive which may hinder the transformation (Rodrigues, 2017). Based on these findings, the list of challenges will be harmonized and validated by conducting interviews with the experts in the future.

In retrospect, HEIs need to adapt to DT changes to work faster, easier, more efficient and effective (Furjan, Strahonja, \& Tomičić, 2018). Technology makes the business of education more complicated and competitive. In order for HEIs to survive, is to be more adaptive, responding quickly to changing expectations. Technologies will keep on evolving and disrupts higher education. Fundamentally, HEI should be more adaptive or be left behind (Lane, Lemoine, Tinney, \& Richardson, 2014).

\subsection{Enterprise Architecture as Enabler to Facilitate Digital Transformation in HEI}

Several researchers highlighted adapting Enterprise Architecture (EA) as a problem-solving tool and enabler for organizational change in supporting DT initiatives (Hafsi \& Assar, 2016; Ylinen \& Pekkola, 2019). The implementation of EA supports the holistic development and management of technologies, information systems, processes, and data. EA is often used to increase efficiency and interoperability within organization. EA is perceived as the practice for planning and designing architecture as well as the glue between business and IT to minimize cost of IT, facilitate business operations effectively and efficiently (Gebayew et al., 2018).

Sandkuhl \& Lehmann (2017) also claimed that EA forms an excellent support for planning DT in HEI because EA oversees the entire architecture more strategically. EA approach should support digitization of products and services and easily adaptable to support DT with new business models and technologies (Bogner \& Zimmermann, 2016). Other than EA able to bridge the gaps and aligning business and IT, EA serves as a guideline in planning DT strategically for HEI (Gat, Kosasi, \& Sulsatri, 2019).

EA is suitable for HEI as it provides a holistic view and planning frame for business and technological changes (Gama et al., 2018). EA constitute a conceptual tool that helps HEI to understand its own structure and 
benefits the integrations of IT systems with educational processes in terms of increase agility of HEIs, better decision making and decreased IT related risks (Benavides et al., 2020). EA can be leverage to structure and manage digital complexity and adapt to DT (Gampfer, 2018).

\section{Conclusion}

DT affects organizations in terms of business models, operational process, organizational structure, culture and managerial. Previous researchers often discuss on DT challenges for HEIs only in the perspective of teaching and learning. This paper, however, looks into a more holistic point of view of HEIs in adapting to DT and facing its challenges. Based on this review, it can conclude that in adapting to DT, the challenges that HEIs facing are adapting to new learning environment and models, stakeholder digital literacy and expectations, lack of digital strategic vision, changes to organizational structure and business processes, digital initiatives and technology barriers, and financial constraints. This paper also proposes, in order to overcome DT adaptation challenges in HEI is by considering EA to facilitate DT initiatives. Hence, EA can be leveraged to support HEI in adapting to DT.

\section{Acknowledgment}

The authors would like to express appreciation for the support of Universiti Teknologi Malaysia and Ministry of Education (FRGS/1/2018/ICT04/UTM/02/12) for providing financial support.

\section{References}

1. Balyer, A., \& Öz, Ö. (2018). Academicians' Views on Digital Transformation in. International Online Journal of Education and Teaching (IOJET), 5(May), 809-830.

2. Benavides, L. M. C., Arias, J. A. T., Serna, M. D. A., Bedoya, J. W. B., \& Burgos, D. (2020). Digital transformation in higher education institutions: A systematic literature review. Sensors (Switzerland), 20(11), 1-23. https://doi.org/10.3390/s20113291

3. Bogner, J., \& Zimmermann, A. (2016). Towards Integrating Microservices with Adaptable Enterprise Architecture. In Proceedings - IEEE International Enterprise Distributed Object Computing Workshop, EDOCW (Vol. 2016-Septe, pp. 158-163). https://doi.org/10.1109/EDOCW.2016.7584392

4. Bond, M., Marín, V. I., Dolch, C., Bedenlier, S., \& Zawacki-Richter, O. (2018). Digital transformation in German higher education: student and teacher perceptions and usage of digital media. International Journal of Educational Technology in Higher Education, 15(1), 48. https://doi.org/10.1186/s41239-018-0130-1

5. Brown, A., Fishenden, J., \& Thompson, M. (2014). Organizational Structures and Digital Transformation. In Digitizing Government: Understanding and Implementing New Digital Business Models (pp. 165-183). London: Palgrave Macmillan UK. https://doi.org/10.1057/9781137443649_10

6. Bughin, J., \& Zeebroeck, N. van. (2017). The Best Response to Digital Disruption. MIT Sloan Management Review, 58(4), 80-86. Retrieved from https://sloanreview.mit.edu/article/the-rightresponse-to-digital-disruption/

7. Buvat, J., Slatter, M., Puttur, R. K., Westermann, G., Bonnet, D., \& Crummenerl, C. (2018). Understanding digital mastery today. Capgemini Digital Transformation Institute.

8. Dahlan, A. R. A., Mukhtar, A. B. A., Ahmad@Alias, N. A. B. A., \& Awang, S. N. B. (2017). Malaysian University of the Future: A Conceptual Business Model. International Journal of Computer Science and Information Technology Research, 5(2), 150-166.

9. Educause. (2018). Report from the 2018 EDUCAUSE Task Force on Digital Transformation | EDUCAUSE. Educause, (November). Retrieved from https://library.educause.edu/resources/2018/11/report-from-the-2018-educause-task-force-ondigital-transformation

10. Furjan, M. T., Strahonja, V., \& Tomičić, K. (2018). Framing the Digital Transformation of Educational Institutions. In 29th Central European Conference on Information and Intelligent Systems (pp. 97-104).

11. Gama, J. A. P., Vega, V. A., \& Neira, A. M. (2018). University Digital Transformation Intelligent Architecture: A Dual Model, Methods and Applications. In 16th LACCEI International MultiConference for Engineering, Education, and Technology (pp. 19-21). https://doi.org/10.18687/laccei2018.1.1.274

12. Gampfer, F. (2018). Managing Complexity of Digital Transformation with Enterprise 
Architecture. In J. S. \& R. B. A. Pucihar, M. Kljajić Borštnar. P. Ravesteijn (Ed.), 31st BLED EConference: Digital Transformation: Meeting the Challenges (pp. 635-641). BLED, SLOVENIA: University of Maribor Press. https://doi.org/10.18690/978-961-286-170-4.44

13. Gat, Kosasi, S., \& Sulsatri, K. (2019). Enterprise Architecture: Key to Successful Digital Business Transformation. In 2019 1st International Conference on Cybernetics and Intelligent System, ICORIS 2019 (pp. 156-161). Denpasar, Bali, Indonesia: IEEE. https://doi.org/10.1109/ICORIS.2019.8874926

14. Gebayew, C., Hardini, I. R., Henry, G., Panjaitan, A., \& Kurniawan, N. B. (2018). A Systematic Literature Review on Digital Transformation. In 2018 International Conference on Information Technology Systems and Innovation (ICITSI) (pp. 1-6). IEEE. https://doi.org/10.1109/ICITSI.2018.8695912

15. Hafsi, M., \& Assar, S. (2016). What enterprise architecture can bring for digital transformation: An exploratory study. In Proceedings - CBI 2016: 18th IEEE Conference on Business Informatics (Vol. 2, pp. 83-89). https://doi.org/10.1109/CBI.2016.55

16. Haggans, M. (2015). The future of the American campus. On the Horizon, 23(1), $25-32$. https://doi.org/10.1108/OTH-11-2014-0038

17. Henriette, E., Feki, M., \& Boughzala, I. (2016). Digital Transformation Challenges. In Mediterranean Conference on Information Systems (MCIS). AIS Electronik Library. Retrieved from https://aisel.aisnet.org/cgi/viewcontent.cgi?article=1033\&context=mcis2016

18. Hussain, A., Mkpojiogu, E.O.C., Yusof, M.M. (2016). Perceived usefulness, perceived ease of use, and perceived enjoyment as drivers for the user acceptance of interactive mobile maps. AIP Conference Proceedings, 1761, art. no. 020051

19. Jauhar, J., Ghani, A.B.A., Joarder, M.H.R., Subhan, M., Islam, R. (2015). Brain drain to Singapore: A conceptual framework of Malaysians' diaspora. Social Sciences (Pakistan), 10 (6), pp. 702-711.

20. Kaminskyi, O. Y., Yereshko, Y. O., \& Kyrychenko, S. O. (2018). Digital Transformation of University Education in Ukraine: Trajectories of Development In The Conditions of New Technological and Economic Order. Information Technologies and Learning Tools, 64(2), 128137.

21. Lane, K. E., Lemoine, P., Tinney, T. M., \& Richardson, M. D. (2014). Modify and Adapt. International Journal of Innovation in the Digital Economy, 5(2), 24-36. https://doi.org/10.4018/ijide.2014040103

22. Limani, Y., Hajrizi, E., Stapleton, L., \& Retkoceri, M. (2019). Digital Transformation Readiness in Higher Education Institutions (HEI): The Case of Kosovo. IFAC PapersOnLine, 52(25), 52-57. https://doi.org/10.1016/j.ifacol.2019.12.445

23. Maltese, V. (2018). Digital Transformation Challenges for Universities: Ensuring Information Consistency Across Digital Services. Cataloging \& Classification Quarterly, 56(7), 592-606. https://doi.org/10.1080/01639374.2018.1504847

24. Microsoft. (2018). Unlocking the Economic Impact of Digital Transformation in Asia Pacific. Microsoft Digital Transformation Study 2018.

25. Nahrkhalaji, S. S., Shafiee, S., Shafiee, M., \& Hvam, L. (2018). Challenges of Digital Transformation: The Case of the Non-profit Sector. 2018 IEEE International Conference on Industrial Engineering and Engineering Management (IEEM), 1245-1249.

26. Nugraha, M. S., Sahroni, D., \& Latifah, A. (2018). Digital Transformation Prospects in Islamic Higher Education: Opportunities, Challenges and Its Impacts. Advances in Social Science, Education and Humanities Research, 261(Atalntis Press), 143-151. https://doi.org/10.2991/icie18.2018.26

27. Parviainen, P., Kääriäinen, J., Tihinen, M., \& Teppola, S. (2017). Tackling the digitalization challenge: how to benefit from digitalization in practice. International Journal of Information Systems and Project Management, 5(1), 63-77. https://doi.org/10.12821/ijispm050104

28. PWC. (2018). The 2018 digital university: Staying relevant in the digital age. Retrieved from https://www.pwc.co.uk/assets/pdf/the-2018-digital-university-staying-relevant-in-the-digitalage.pdf

29. Reis, J., Amorim, M., Melão, N., \& Matos, P. (2018). Digital transformation: A literature review and guidelines for future research. Advances in Intelligent Systems and Computing, 745, 411-421. https://doi.org/10.1007/978-3-319-77703-0_41

30. Rodrigues, L. S. (2017). Challenges of Digital Transformation in Higher Education Institutions: A brief discussion. In K. Soliman (Ed.), Vision 2020: Sustainable Economic Development, Innovation Management, and Global Growth (pp. 4490-4493).

31. Sandkuhl, K., \& Lehmann, H. (2017). Digital Transformation in Higher Education - The Role of 
Enterprise Architectures and Portals. Lecture Notes in Informatics (LNI), 49-60. Retrieved from https://dl.gi.de/bitstream/handle/20.500.12116/119/paper04.pdf?sequence=1

32. Tarabasz, A., Selaković, M., \& Abraham, C. (2018). The Classroom of the Future: Disrupting the Concept of Contemporary Business Education. Entrepreneurial Business and Economics Review, 6(4), 231-245. https://doi.org/10.15678/EBER.2018.060413

33. Trifonov, V. A., \& Shorokhova, N. . (2019). University Digitalization- A Fashionable Trend or Strategic Factor of Regional Development? European Proceedings of Social and Behavioural Sciences, 59, 1003-1013. https://doi.org/10.15405/epsbs.2019.04.109

34. Ylinen, M., \& Pekkola, S. (2019). A process model for public sector IT management to answer the needs of digital transformation. Proceedings of the 52th Annual Hawaii International Conference on System Sciences, 10.

35. Zimmermann, A., Schmidt, R., Bogner, J., Jugel, D., \& Möhring, M. (2018). Software evolution for digital transformation. ENASE 2018 - Proceedings of the 13th International Conference on Evaluation of Novel Approaches to Software Engineering, 2018-March (Enase), 205-212. https://doi.org/10.1109/HICSS.2012.226

36. Zulfikar, M. W., Umri, H. U. B. A., Hashim, A. I., \& Dahlan, A. R. . (2018). A business case for digital transformation of a Malaysian-based University. In Proceedings - International Conference on Information and Communication Technology for the Muslim World 2018, ICT4M 2018 (pp. 106-109). https://doi.org/10.1109/ICT4M.2018.00028 